\title{
INVESTIGATION OF SUSPENDED SOLIDS IN WATER FOR COKE EXTINCTION
}

(c) O.L. Borisenko, PhD in technical sciences, O.S. Malysh, PhD in technical sciences, M.I. Bliznyukova (State Enterprise "Ukrainian State Research Institute for Carbochemistry (UKHIN)", 61023, Kharkov, Vesnina st., 7, Ukraine), Ye.N. Popov (PJSC «AVDIIVKA COKE», 86066, Avdiivka, Industrial str., 1, Ukraine)

The article is devoted to the results of work for the study of the composition and quantitative content of suspended solids (SS) in the wastewater of coke plants before and after biochemical purification plants (BPP), as well as in other waters involved in the process of coke extinction. The characteristic indicators have been investigated of waters before and after BPP of five coke-chemical enterprises of Ukraine, as well as the chemical composition of suspended solids in water after BPP, etc.

It is shown that SS in water after BPP is represented mainly by activated sludge, which is partially oxidized to CO2 when water is supplied to hot coke. The rest activated sludge is returned with water condensate to the settling tank of the extinction tower and, thus, is not emitted into the atmosphere in the form of SS.

In addition to sludge, the particles of coke, coal and products of the equipment corrosion are present in the purified water after the BPP and in the water of the extinction tower settling tank. The possibility of the presence of concrete particles is also not excluded. To establish the nature of solid particles, their elemental composition and ash composition has been determined. In particular, it was found that the ash composition of suspended solids from water after BPP quantitatively differs from the both of ash composition of coal concentrates and the composition of concrete. For example, the mass fraction of silicon dioxide in the suspended solids of water after BTH is much lower than in concrete and in ash of coal concentrates. The detected predominance of iron (III) oxide in the composition of SS ash after BPP is explained by the presence in the selected samples of products of the equipment corrosion.

Based on our research, it is proposed to make changes in the normative document "Technological standards of permissible emissions of pollutants from coke ovens", namely in chapter IV "Operating conditions of coke ovens" par. 8: to exclude such a normative value as the content of suspended solids in water after BPP, which is submitted for coke extinction.

Keywords: water for coke extinction, water after biochemical purification, suspended solids (SS), content, chemical composition, elemental composition, ash composition.

Corresponding author A.L. Borisenko, e-mail: zd@ukhin.org.ua 